\title{
Saúde mental e classe social: CAPS, um serviço de classe e interclasses
}

\section{Mental heath and social class: CAPS (Psychosocial Care Centers), a service that is oriented to a social class}

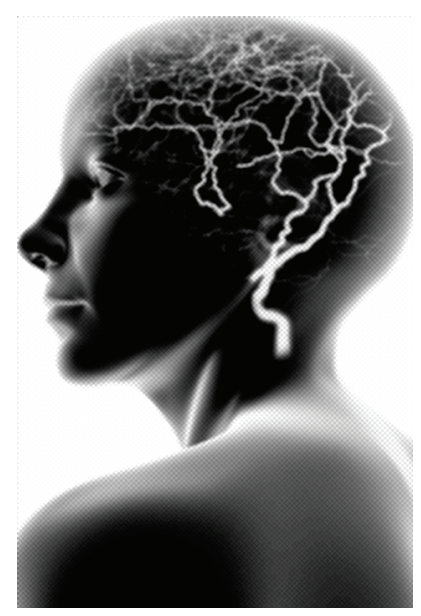

\author{
Lucia Cristina dos Santos Rosa* \\ Rosana Teresa Onocko Campos**
}

Resumo: São analisadas as manifestações de classe social no cotidiano de dois centros de atenção psicossocial, um localizado no Nordeste e outro no Sudeste do Brasil, baseado na teoria do cotidiano de Agnes Heller. Trata-se de uma pesquisa de natureza qualitativa, com triangulação de técnicas, e o emprego privilegiado de grupos focais, tendo por sujeitos os usuários, os familiares e os profissionais. O CAPS é contornado por diferentes classes sociais, mas constitui um serviço focado nos segmentos pobres.

Palavras-chave: Classe social. Saúde mental. Reforma psiquiátrica.

\begin{abstract}
It examines the manifestations of social class in two daily psychosocial care centers, one located in the Northeast and one in southeastern Brazil, based on the theory of everyday life of Agnes Heller. This is a qualitative research with triangulation techniques, privileged with the use of focus groups, with the subject users, relatives and professionals. The caps are bypassed by different social classes, but constitutes a service focused on the poorest segments.
\end{abstract}

Keywords: Social class. Mental health. Psychiatric Reform.

* Doutora em Serviço Social pela Universidade Federal do Piaú (UFPI), Departamento de Serviço Social.E.mail: luciacsrosa@yahoo.com.br.

** Doutora em Saúde Coletiva pela Universidade Estadual de Campinas (Unicamp), Brasil. E-mail: rosanaoc@mpc.com.br. 


\section{Introdução}

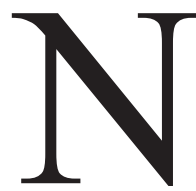

o mundo ocidental, a partir da sociedade moderna, burguesa e capitalista, o modelo de atenção à pessoa com transtorno mental esteve circunscrito pela segregação/exclusão social, condensado no formato hospitalocêntrico das "instituições totais" (Goffman, 1992), que abarcava a totalidade da vida do ser humano, impedindo o seu convívio social. Além disso, esse modelo assegurava determinado rol de serviços sociais, tais como o abrigo e a assistência médica, mas suprimia a liberdade, obstaculizando a assunção da condição cidadã desse segmento. Vários movimentos, orientados por diferentes tradições teóricas, emergem para alterar esse quadro nos Estados Unidos e na Europa, pós-Segunda Guerra Mundial.

Com a redemocratização da sociedade brasileira, a partir da década de 1970, um novo cenário se abre, com a emergência do movimento da reforma psiquiátrica, exigindo outra relação do "louco" com a sociedade e o reconhecimento da pessoa com transtorno mental, no estatuto de cidadania, ganhando projeção a luta por seus direitos civis, sem desconsiderar seus direitos sociais.

O movimento brasileiro é influenciado pela experiência italiana da tradição basagliana (Amarante, 1996), que coloca a enfermidade entre parênteses, evidenciando o sujeito enfermo e seu contexto de vida. Constrói seu objeto sobre a complexidade da "existência-sofrimento" (Rotelli, 1990) das pessoas com transtornos mentais, articulando-a com suas condições de reprodução social e enfatizando o processo de invenção/produção da saúde.

Nesta leitura, a questão a ser enfrentada é a emancipação, a ampliação do poder de trocas sociais das pessoas com transtornos mentais, não a obstinação terapêutica pela cura ou a reparação, mas a reprodução social, a reinscrição dessas pessoas no mundo social.

Tais perspectivas convergem, irradiam-se e se materializam no próprio conceito ampliado de saúde, advogado pelo Sistema Único de Saúde e reforçado pela Constituição federal de 1988, em que os determinantes sociais do processo saúde-doença-cuidado ganham destaque. Reorientando o modelo assistencial anterior, emerge a atenção comunitária, tendo os centros de atenção psicossocial — CAPS - como carro-chefe do novo modelo de cuidado, considerado equipamento por excelência para organizar a rede assistencial e articular as condições para a reinserção da pessoa com transtorno mental na sociedade. 
Em termos paradigmáticos, a nova perspectiva e prática circunscreve o amplo campo denominado de atenção psicossocial, um termo polissêmico, mas, no contexto do presente texto, compreendido como

um processo que implica a abertura de espaços de negociação para o paciente, para sua família, para a comunidade circundante e para os serviços que se ocupam do paciente: a dinâmica da negociação é contínua e não pode ser codificada de uma vez por todas, já que os atores (e os poderes) em jogo são muitos e reciprocamente multiplicantes". (Saraceno, 1999, p. 112)

Saraceno equipara o conceito de atenção psicossocial à cidadania, entendendo-os como sinônimos.

Nesta perspectiva, vários elementos assumem papel de destaque na evolução de um transtorno mental, assim como na estratégia de intervenção em saúde mental. Saraceno (1999) classifica esses elementos dividindo-os em variáveis fortes e variáveis sombra. As primeiras são delimitadas por: diagnóstico, idade, agudeza ou cronicidade do quadro e história da enfermidade (p. 21). As variáveis denominadas como "sombra" não são menos importantes, mas contornam uma gama de elementos que se relacionam com os recursos individuais da pessoa com transtorno mental: "o nível de capacidade intelectual e o grau de informação" da pessoa com transtorno mental, seu status social, sua condição de solidão ou não e o sexo (p. 21).

Entre os recursos do contexto destacam-se o nível de comprometimento relacional dos familiares, nível de solidariedade ou hostilidade da rede de parentesco ou de vizinhança, o status social do grupo familiar e nível de integração ou desintegração social do meio em que vive.

Desse modo, a pessoa com transtorno mental é restituída em sua integralidade, e o foco da atenção dos profissionais de saúde mental se amplia para além dos sintomas e dos medicamentos, para outras dimensões sociais da vida, que englobam a "existência sofrimento". Assim, os determinantes sociais do processo saúde-doença-cuidado ganham ênfase, e o social passa a ser uma dimensão que precisa ser evidenciada na intervenção cotidiana de saúde mental, a partir da reconstituição das múltiplas referências que contornam a identidade da pessoa com transtorno mental e de seus familiares, destacando-se no escopo do presente texto a classe social subjacente ao status, tal como expresso por Saraceno.

Classe social é um termo secundarizado no movimento de reforma psiquiátrica brasileiro, porém que conforma as relações sociais entre as pessoas que atuam 
ou utilizam os serviços da saúde mental. É um conceito abstrato, apropriado por várias perspectivas teóricas, mas inacabado no interior dos estudos marxianos.

Santos (1985), como representante da tradição marxista, a concebe como "agregados básicos de indivíduos numa sociedade, os quais se opõem entre si pelo papel que desempenham no processo produtivo, do ponto de vista das relações que estabelecem entre si, na organização do trabalho, e quanto à propriedade" (p. 41). Constituem-se como principal motor de mudança social. O supracitado conceito se generalizou no senso comum e atravessa os indivíduos, suas identidades e suas vivências pessoais, sobretudo pelas diferentes expressões das desigualdades sociais, reforçadas pelo Estado, a partir da constituição da cidadania ocupacional, na década de 1930, que obstaculizou historicamente os efeitos redistributivos das políticas sociais, pois

[...] Direitos que recriam desigualdades, pela sua vinculação profissional são também direitos que não se universalizam e sobrepõem às diferenças sociais uma outra clivagem que transforma em não cidadãos os que escapam às regras do contrato. Esses são os não iguais, os que não estão credenciados à existência cívica justamente porque privados de qualificação para o trabalho. São os pobres, figura clássica da destituição. (Telles, 1999, p. 94)

As desigualdades sociais na saúde mental materializam-se a partir de diferentes formas de acesso a cuidados, determinadas pela origem de classe da pessoa com transtorno mental.

Em parte da literatura europeia e latino-americana, o reconhecimento da predominância do modelo hospitalocêntrico na assistência psiquiátrica pública é acompanhado pelo seu endereçamento específico de classe social como uma resposta do Estado à questão social posta por segmentos da classe trabalhadora, os loucos pobres.

Robert Castel (1978), ao analisar a realidade francesa, explicita que o poder da psiquiatria em seu nascedouro orientou-se, sobretudo, para os loucos pobres, denominados pelo autor como indigentes.

[...] psiquiatria para os pobres, mas também pobre psiquiatria, que é obrigada a "escolher" seus sujeitos em função de critérios essencialmente negativos: os que estão mais afastados da cultura médica, os que têm mais chance de se revelar incuráveis, os que são os mais pobres, tanto em dinheiro como em insight, para recompensar o médico. (p. 173) 
Tais características acompanharam historicamente a assistência psiquiátrica, diferenciada conforme a origem de classe dos usuários dos serviços. Para os pobres, os serviços públicos; para os segmentos mais aquinhoados economicamente, os serviços da medicina liberal, mais elitizados, de melhor qualidade e preservadores da autonomia da pessoa com transtorno mental e, consequentemente, de seus direitos.

Franco Basaglia (1985) identifica cenário semelhante na realidade italiana ao mostrar que o modelo hospitalocêntrico/segregador tem sua origem na posição de classe social de seus usuários

[...] podemos afirmar desde já que ele é, antes de mais nada, um homem sem direitos, submetido ao poder da instituição [...] tal exclusão ou expulsão da sociedade resulta antes da ausência de poder contratual do doente (ou seja, de sua condição social e econômica) que da doença em si. (p.108)

Dessa maneira, conclui que o poder da instituição total, uma instituição que se considera violenta, "aplica-se unicamente àqueles que não têm outra alternativa que não o hospital psiquiátrico [...] devido exatamente ao fato de serem socioeconomicamente insignificantes" (p.108).

No contexto argentino, Moffatt (1991) também constata o mesmo cenário, buscando resgatar a "cultura criolla" e as psicoterapias populares.

Resende (1990), ao retratar a origem de classe da população psiquiátrica, no modelo hospitalocêntrico brasileiro, confirma que a criação do hospício se coaduna com a forma como a questão social era abordada no período da inauguração desse dispositivo - como caso de polícia - como um assunto ilegal, subversivo e, portanto, tratado como crime e desordem e, por isso, reprimido. Seus agentes eram detidos e reclusos em cadeias públicas, excluídos do cenário social. A função principal do hospício, nessa fase, segundo o mesmo autor, era a de remover, excluir e sanear a cidade de um segmento que potencialmente era considerado desordeiro/ perigoso, improdutivo para o capital.

Os loucos, antes da fundação do hospício, se tranquilos, eram acolhidos pela sociedade e assim podiam circular livremente; porém, se agitados e agressivos, eram reclusos nas cadeias públicas. Além do critério comportamental, a classe social também definia a assistência destinada ao louco, pois os ricos eram tratados domiciliarmente ou enviados para tratamento na Europa. No decorrer do artigo, o autor vai mostrar como todo o percurso do modelo assistencial psiquiátrico brasileiro público se destina aos "loucos pobres", ampliando-se paulatinamente para os 
trabalhadores rurais e urbanos, sobretudo na década de 1970, quando há intenso desgaste da força de trabalho, sendo caracterizada como uma assistência massificada, violadora de direitos e destituidora de identidades.

Agnes Milles (1982), ao discutir "classe social e doença mental", promovendo uma revisão bibliográfica, constata que a literatura sinaliza a forte associação entre classe social e enfermidades mentais. Constata ainda que há diferentes tipos de tratamento, de acordo com a classe social da pessoa, sendo limitado às pessoas designadas pela autora como "de classe inferior", atendimento custodial, enquanto para os segmentos de melhor renda, era oferecido um atendimento mais prolongado e dispendioso. Apesar disso, a autora mostra que os estudos indicam a tendência de haver, mesmo para segmentos de melhor renda, uma mobilidade social descendente para a pessoa com transtorno mental, à medida que este se consolida na vida do enfermo, levando à deterioração crescente, que é acompanhada por empregos de menor status social, remuneração e até o desemprego. Segundo a autora, "as camadas inferiores" seriam "deixadas para trás" (p. 158), não havendo mobilidade social em virtude mesmo da posição ocupada na escala social, anterior à eclosão da enfermidade.

Milles admite, entretanto, que a mobilidade social também é influenciada pelo estigma, que historicamente acompanhou o transtorno mental e a pessoa enferma, levando a uma crescente desvantagem social.

Dunningham (1988), ao analisar a relação entre classes sociais e transtornos mentais, em Salvador (BH), numa perspectiva epidemiológica, sinaliza que há relação mais estreita entre transtornos mentais com estilos de vida, consequentemente com estratos sociais, do que com classes sociais.

Sampaio (1998), ao explorar a epidemiologia e sua imprecisão no processo saúde/doença mental, buscando contribuir na articulação entre subjetividade e objetividade para o campo, a partir do método dialético, esclarece que não há uma teoria de classe social em Karl Marx, que deixou seu trabalho inacabado em relação a essa categoria, deixando apenas pistas para várias direções analíticas. $\mathrm{O}$ autor concebe classe social como "uma categoria teórica primeira que explica a heterogeneidade estrutural da população humana e seus vários modos de gozar a vida, sofrer a vida, adoecer e morrer (p. 74).

Ludermir (2008), ao discutir as desigualdades de classe e gênero na saúde mental, conclui que os transtornos mentais comuns prevalecem nos segmentos de desempregados de baixa renda, atingindo principalmente as pessoas do sexo masculino, vulnerabilizando, sobremodo, tais estratos. 
Nunes (2010), ao realizar um balanço da pesquisa pioneira sobre classe social e doença mental, que deu origem à sociologia da doença, de autoria de Hollingshead e Redlich, respectivamente sociólogo e psiquiatra, nos Estados Unidos, nos anos 1950, informa que os resultados do estudo mostravam a intensa associação entre classe social e doença mental, que se confirmava com a introdução e a comparação de outras variáveis.

Todavia, a pesquisa dos autores acima e a da revisão bibliográfica realizada por Milles (1982) não associam as dimensões de classe social dos usuários dos serviços às origens de classe dos profissionais de saúde mental, oriundos, comumente, de frações médias da sociedade.

Com outro direcionamento nas discussões de classe social, em 1986, é lançada, no Brasil, a segunda edição do livro de Luiz Fernando D. Duarte, Da vida nervosa nas classes trabalhadoras urbanas, que mostra as particularidades da vivência com o transtorno mental entre as diferentes classes sociais, traduzida em culturas e subculturas singulares. $\mathrm{O}$ autor, embora conceba classe social a partir das relações sociais de produção, definindo classes trabalhadoras como os segmentos que dependem da venda da sua força de trabalho para se reproduzir mas também se autoidentificam positivamente como trabalhadores, parece se fixar mais nas dimensões de acesso aos bens simbólicos, sobretudo à escolarização, para contrapor a ideologia do individualismo, cuja ênfase recai no indivíduo intimista moderno. Este conforma o saber configurado pelo autor como "psicológico", típico dos segmentos "letrados", de estratos médios e altos da sociedade, à cultura do "nervoso", que seria inerente ao primeiro grupo, o qual, segundo o autor, se orienta na sociedade por uma cultura "das classes trabalhadoras urbanas", fundamentada na hierarquia, numa visão holista, "não individualista, mas relacional da pessoa, conformando um saber baseado nas "perturbações físico-morais", fundado no "código do nervoso", que abrange as alterações da pessoa como um todo, incluindo suas relações sociais.

Com a crescente difusão midiática e a padronização de valores e visões de mundo "moderno e pós-modernos", há uma tendência de o modelo do psicológico se tornar hegemônico, sendo incorporado por todos os grupos sociais, muito embora possa persistir resquício do modelo do nervoso, coexistindo de maneira conjugada.

Fonseca (2008), ao efetivar um balanço literário da perspectiva do "código do nervoso" no contexto brasileiro, sinaliza para as tensões assistenciais, que tendem a se agravar entre profissionais de saúde mental e o público majoritário dos serviços 
públicos de saúde mental, em função de os primeiros serem orientados por uma concepção de indivíduo típico da configuração psicológica moderna, intimista, enquanto os usuários predominantes do serviço orientar-se pelo "código do nervoso", resultando em mal-entendidos, que se perpetuam "notadamente nos serviços públicos, no qual a classe média - representada, majoritariamente pelos profissionais de saúde - tende a compreender as expressões do sofrimento das classes populares, de acordo com seus próprios códigos" (p. 182).

Ou seja, o etnocentrismo tende a prevalecer na relação entre profissionais e usuários majoritários da assistência pública, contornada por concepções diferenciadas a partir da origem de classe social.

A autora chama ainda a atenção para as dificuldades de a política de saúde mental brasileira incorporar e equacionar tal tensão, em virtude das contradições inerentes ao campo $p s i$, bem como aquelas próprias das necessidades dos usuários dos serviços públicos de saúde do país, inclusive intermediado pelas dificuldades de diálogo entre dois códigos distintos.

Como visto no levantamento bibliográfico realizado, observou-se que três perspectivas tendem a orientar os estudos relacionando classe social e enfermidades mentais. De um lado encontram-se os estudos que mostram que a assistência em saúde mental, sobretudo a de natureza público-estatal, tem uma clivagem preponderante de classe social. Ou seja, é destinada dos segmentos pobres e trabalhadores empobrecidos da população. Não se conduz para uma ação universal, pluriclassista e, consequentemente, pende para uma ação parametrada pela violação de direitos humanos, uma assistência pobre para os pobres.

Dirige-se para a análise da identidade da pessoa com transtorno mental em suas origens de classe e o público destinatário da assistência pública de saúde mental. A outra vertente inclina-se para a associação entre classe social e transtorno mental, mostrando a distribuição desigual das enfermidades, segundo a origem econômica das pessoas com transtorno mental. A primeira e a segunda perspectiva se conjugam, pois encontram, entre os segmentos mais pobres da população, a prevalência dos transtornos mentais e, na assistência psiquiátrica, o mesmo público como alvo.

De outro lado, situam-se os estudos que buscam distinguir formas culturais específicas no conceber e viver com o transtorno mental, constituindo socialmente dois códigos culturais particulares, segundo a posição de classe do ator social. Destarte, a configuração do psicológico manifesta o modo de ser dos segmentos 
médios/altos e letrados, enquanto o "código do nervoso" representaria as peculiaridades das classes trabalhadoras urbanas. Tais códigos se manifestam no dia a dia assistencial, tensionando as relações entre profissionais e usuários dos serviços, tendo em vista a identidade dos primeiros estar imbricada com os saberes psicológicos, e os segundos, com o modelo do nervoso.

Tais perspectivas somam-se e necessitam de maiores investimentos, visto a assunção da saúde, a partir de 1988, como um direito de todos, portanto universal e dever do Estado, no cerne de uma nova compreensão da cidadania, considerada plena. Nesse horizonte, os serviços públicos de saúde destinam-se potencialmente a todos, tendo crescentemente que abarcar a pluralidade cultural e de condição social.

\section{Contextualizando a pesquisa e o campo empírico}

O cotidiano é a vida de todo ser humano, como esclarece Heller (1989). É concomitantemente espaço da trivialidade, da reprodução do status quo e arena da mudança social. Todo ser humano dela participa, colocando em ação "todos os seus sentidos, todas as suas capacidades intelectuais, suas habilidades manipulativas, seus sentimentos, paixões, ideias, ideologias" (Heller, 1989, p. 17).

Para a autora, a espontaneidade é a tendência que domina a vida cotidiana, levando o ser humano a muitos atos repetitivos e mecânicos, em função de assimilar o "comportamento consuetudinário e do ritmo da vida, mas também [...] faz-se acompanhar por motivações efêmeras em constante alteração" (p. 30). Logo, a naturalização do acontecer histórico e a ausência de problematização do cotidiano estão muito presentes. Ou seja, o cotidiano acontece com uma dose significativa de alienação, uma vez que é comandado pelo senso comum e pela ultrageneralização, que se incorpora em pensamentos e comportamentos, por meio de estereótipos, analogias e esquemas instituídos e institucionalizados. Neste contorno, os pré-conceitos fazem parte do cotidiano. Todavia, a mesma autora destaca que há possibilidade de tal banalização e reificação do status quo se alterar a partir de uma dimensão crítica que permita a suspensão da cotidianidade. Tal processo, entretanto, ocorre de maneira descontínua, pois a mudança histórica e, sobretudo, nas dimensões cultural e dos costumes, ocorre de maneira lenta e é atravessada por processos contraditórios, não lineares, mas dinâmicos, abrangendo a coexistência do velho e do novo, em permanente disputa por instituir-se. 
O cotidiano incorpora o novo, aqueles fatos ou acontecimentos que instituem ruptura com o já dado e que ganham maior visibilidade em processos de intensa mudança, que causam forte impacto por alterar rápida e intensamente a realidade e mobilizar objetiva e subjetivamente os protagonistas, tal como ocorreu no início do processo de reforma psiquiátrica, em que todos os atores sociais se mobilizavam contra o Estado ditatorial e um modelo assistencial mercantil e visivelmente violador de direitos humanos.

Simultaneamente, os processos de mudança social também convivem com elementos da velha ordem em processo de contestação, com seus protagonistas atuando no sentido de restabelecer a ordem ameaçada. Mudanças em processos culturais são mais morosos, alterando-se de maneira lenta. Há, consequentemente, não apenas resistência à mudança social, mas persistências, elementos de permanência, preservadores da ordem social.

É o que se observa contemporaneamente na coexistência tensa entre um novo estatuto, posto pelas conquistas sociais, a partir do processo de redemocratização da sociedade brasileira, materializados na Constituição de 1988, e todo o arcabouço legal e institucional, impresso na perspectiva de uma cidadania plena e universal. E os riscos de regressão de todo avanço consignado a partir da assunção do ideário neoliberal, impondo o Estado mínimo e restrição aos gastos sociais, forjando a cidadania do consumidor.

Contemporaneamente, a arena é incerta, desenhada pelos impasses postos pelo avanço neoliberal em um contexto em que os direitos sociais pouco se efetivaram e encontram-se ameaçados. Contraditoriamente, como avalia Dagnino (2008), a democracia se consolidou e o Estado se ampliou, incorporando a participação da sociedade civil, que se pluralizou e se complexificou, tornando-se heterogênea, presidida por vários valores que podem ser apropriados e ressignificados, como vem ocorrendo, na perspectiva de reafirmar projetos que reforcem a saúde como uma mercadoria, embasados inclusive por políticas focalizadas. Nesse cenário é que se desenvolveu a pesquisa norteada pelas seguintes indagações: com a universalização do Sistema Único de Saúde e implementação da reforma psiquiátrica no contexto brasileiro, outras classes ou frações de classe passaram a utilizar os CAPS/ serviços públicos de saúde mental? Como as identidades de classe social se manifestam no cotidiano assistencial?

A pesquisa de natureza qualitativa foi desenvolvida no período de agosto de 2011 a julho de 2012. Baseou-se em triangulação de técnicas, adotando-se grupos 
focais, observação participante, análise documental e entrevista semiestruturada com usuários, familiares, profissionais e gestores. Os grupos focais constituíram a técnica privilegiada, concebida como "uma técnica de coleta de dados, que parte de encontros grupais entre pessoas que compartilham traços comuns" (Miranda et al., 2008, p. 250). A pesquisa foi desenvolvida em dois centros de atenção psicossocial, CAPS, um localizado no Sudeste e outro no Nordeste do país. O segundo não conta com clínicas particulares em saúde mental.

As informações foram tratadas por meio da metodologia da análise de conteúdo (Bardin, 1979), sendo adotada a técnica de análise temática.

O projeto de pesquisa, em conformidade com a Resolução n. 196/96, do Conselho Nacional de Saúde, para efeitos do trabalho de campo na região Sudeste, foi submetido ao Comitê de Ética da Faculdade de Ciências Médicas da Unicamp, em 9 agosto de 2011, recebendo Parecer CEP n. 799/2011, sob CAEE 0717.0.146.000-11, tendo sido aprovado e homologado em reunião de 23 de agosto do mesmo ano. Simultaneamente, para efeitos do trabalho de campo na região Nordeste, foi submetido ao Comitê de Ética do Instituto Camillo Filho, sob Protocolo n. 438/11 e CAEE 0063.0.044.000-11, sendo aprovado em 7 de novembro de 2011.

\section{Mediação de classe social no cotidiano assistencial em saúde mental}

Para analisar o impacto da universalização do Sistema Único de Saúde no contexto brasileiro, a partir da utilização dos serviços dos CAPS por outras classes ou frações de classe, exploraram-se as manifestações e vivências a partir da origem de classe social dos usuários, familiares e profissionais dos dois serviços pesquisados.

Inicialmente, buscou-se apreender como concebiam classe social. A seguir, como se autoclassificavam, em termos de classe social, e como classificavam o público majoritário dos CAPS. As diferentes formas de apropriação dos CAPS pelas pessoas de diversas origens de classe social também constituíram foco de análise.

Predominou uma concepção baseada em critérios econômicos, segundo determinadas estratificações sociais, que colabora no entendimento de classe social, mas sem abarcar toda complexidade do conceito.

Houve uma aproximação na forma de conceber dos diferentes sujeitos da pesquisa de ambos os CAPS, norteados principalmente por questões financeiras, 
particularmente pela remuneração, pautadas pelo salário mínimo, para agrupar os diferentes segmentos sociais. A vertente marxista pareceu orientar um número majoritário de profissionais na sua definição de classe social, haja vista o grupo da região Sudeste reconhecer classe social a partir da inserção no trabalho, e o grupo da região Nordeste, a partir da inserção no modo de produção, como produtores versus assalariados ou trabalhadores proprietários. O grupo de profissionais do turno da tarde da região Nordeste remeteu inicialmente a conceituação de classe social ao assistente social, o que sinaliza certa distância da clínica ampliada, que abarca o social, uma vez que mantém o conceito como algo mais apropriado a determinado núcleo de formação. $\mathrm{O}$ grupo da região Sudeste estratificou as classes sociais em níveis A, B, C, enquanto o da região Nordeste processou como classe alta, média e baixa, o que também sinaliza para convergências.

A base salarial para classificar as diferentes classes sociais, adotada pelos principais centros de pesquisa do país, parece ter se generalizado no senso comum.

O Censo Demográfico/IBGE, como a principal referência brasileira em estudos demográficos, tem por base o "rendimento nominal mensal da pessoa de dez anos ou mais de idade" (Censo Demográfico/IBGE, 2010, p. 33), considerando o salário mínimo. Baseia-se num sistema adotado internacionalmente. Estabelece sete classes de rendimentos nominais mensal domiciliar: "sem rendimentos a $1 / 4$; mais de $1 / 4$ a $1 \frac{1}{2}$; aos de $1 / 2$ a 1 ; mais de 1 a 2; mais de 2 a 3 ; mais de 3 a 5 ; mais de 5 " (IBGE, 2010). Mas ao rendimento auferido associam outros elementos relacionados a vários fatores, entre os quais o número médio de moradores por domicílio, número de cômodos, sexo do responsável pelo domicílio, tipo de relação ou de convivência dos diferentes moradores com a pessoa responsável, entre outros vários aspectos da qualidade de vida expresso em condições habitacionais (permanentes ou improvisados/próprios, alugados ou cedidos) e saneamento básico (detalhado em abastecimento de água, esgotamento sanitário e coleta de lixo e energia elétrica).

Outros critérios quantificáveis foram invocados pelos sujeitos da pesquisa para definir classe social, destacando-se o número de pessoas em uma família, ter ou não residência própria, local de moradia, entre outros.

Muito embora o assalariamento tenha contornado de maneira significativa a definição de classe social, colocando a maioria dos profissionais e usuários/ familiares como parte da classe trabalhadora, não proprietária dos meios de pro- 
dução, ou classe "baixa", outros elementos, sobretudo os valores sociais retratados em bens simbólicos, tais como o capital educacional, também contribuíram para complexificar a inserção de classe social de cada grupo de interesse no CAPS. Entretanto, apesar da relativa homogeneidade entre as diferentes classes ou frações de classe social, que preponderou no entendimento da maioria dos sujeitos da pesquisa, há heterogeneidade cultural, em estilos de vida e concepção de mundo.

Segmentos de usuários e familiares comumente situaram-se entre os segmentos de baixa renda ou entre as frações de classe "média baixa". Igualmente entre os trabalhadores do equipamento observaram-se que os trabalhadores de nível superior tendem a pertencer preponderantemente aos segmentos médios e os de nível técnico/médio entre os segmentos de baixa renda ou renda média baixa, com alguns se identificaram. Os primeiros, identificando-se predominantemente com os estratos médios da sociedade, enquanto entre os segundos, alguns se vinculavam com estratos médios, outros, com os segmentos de baixa renda, sinalizando para ações interclasses no interior da própria equipe de saúde mental, o que comumente constitui fonte de tensão e até mesmo sofrimento.

Como observa Campos e Baccari (2011), os profissionais de nível médio ressentem-se da desvalorização de seu trabalho na própria equipe, o que é fonte de sofrimento, posto que na hierarquia das equipes as relações de poder pendem favoravelmente aos profissionais de nível superior, que comumente deliberam acerca dos rumos assistenciais. Nesse cenário, nas equipes multiprofissionais se expressam as desigualdades sociais que comandam a sociedade.

Logo, entre os trabalhadores há também as tensões e disputas inerentes a uma sociedade cindida em classes sociais, o que se reproduz nas relações de poder, a partir da apropriação de um cabedal de conhecimentos e distintivos sociais, a exemplo de títulos universitários.

Igualmente, entre os trabalhadores e os usuários, observou-se a mesma reprodução, para além das questões etnocêntricas implicadas no embate entre o modelo psicológico e do modelo nervoso. Como explicita Saffioti (2004), "uma classe negocia com a outra por meio de seus representantes" (p. 82), que se incorpora na dinâmica social por intermédio das pessoas, em suas atuações cotidianas.

Para efeitos da pesquisa, a proposta inicial não objetivava esgotar o debate sobre classe social, mas ter uma visão panorâmica de como os sujeitos da pesquisa concebiam classe social, na construção e interação coletiva com seus pares e com 
os usuários dos serviços. Partiu-se do pressuposto de que a forma como profissionais, usuários e familiares se autoidentificavam e classificavam os outros sujeitos com os quais interagiam no dia a dia permitiria analisar tais atravessamentos na compreensão do cotidiano assistencial e seus impactos na mudança ou permanência da ordem social.

Nesse diapasão, observou-se que houve uma leitura etnocêntrica entre os dois grupos de profissionais de nível superior, de ambas as regiões, ao julgar a priorização dos padrões de consumo entre os pobres, centrado em bens duráveis, como carro e eletrodomésticos, havendo um enfoque de valor negativo das escolhas no emprego do orçamento familiar. Tal fato pode se explicar pela padronização de critérios econômicos e ideológicos para classificar os distintos segmentos ou frações de classe social que imperam na sociedade brasileira, desconsiderando que os segmentos de baixa renda partilham os mesmos valores da sociedade em geral. Afinal, como informa a musica dos Titãs, Comida, "a gente não quer só comida".

Usuários e familiares dos dois equipamentos também se orientaram, sobretudo por critérios econômicos, para definir classe social como alta, média e baixa, a partir da condição salarial e do nível de estudo. O grupo da região Nordeste se diferenciou, principalmente entre os familiares cuidadores e usuários, ao discutir outras subdivisões entre as classes "baixas", a partir de diferentes gradações. Considerada por alguns como "sub-humanas", por outros como miseráveis, pobres, diaristas, trabalhadores rurais sem trabalho, "pobres privilegiados", outros ainda como beneficiários do Bolsa Família. Uma visão mais dual da sociedade, cindida entre ricos e não ricos, classe alta e baixa, presidiu a visão de mundo dos profissionais dessa região, o que denota maior reconhecimento da linha de pobreza no contexto nordestino, em suas variações absoluta e relativa. Mas a pobreza não é remetida às relações sociais, que destituem determinados segmentos dos efeitos distributivos em relação ao que foi coletivamente produzido como riqueza por todos na sociedade. As relações políticas que se expressam na pobreza, agravando-a pela sua frequente conjugação a serviços públicos de baixa qualidade e que não permitem superar tal condição, são comumente ignoradas.

O grupo de usuários da região Sudeste destoou ao remeter a concepção de classe social a critérios mais subjetivos e políticos, como uma classe que "vive junto, respeita e é respeitada", ou seja, é democrática. A partir da junção de classe 
com o adjetivo social, inferiu que a classe é a educada, expressa no saber viver com a diferença, com respeito, preservando a dignidade. Então, classe social se expressa em ter classe, isto é, ter educação, saber respeitar a todos indistintamente, haja vista a vivência do estigma contornar o cotidiano de vida desse segmento.

A autoclassificação em termos de classe social de usuários e familiares dos dois serviços oscilou igualmente entre classe "baixa" e "média baixa". Todavia, alguns familiares cuidadores do CAPS da região Nordeste se autodeclaram de maneira mais enfática como pobres, empregando termos como "pobre lascado". Outros se autodenominaram como "pobre privilegiado", por ter saúde e poder manter sua condição de provedor de renda para o grupo familiar. Há, consequentemente, uma perspectiva de comparação sempre com os "de baixo", os que estariam em situação ainda pior nas suas condições econômicas e sociais, visto o entendimento de que "tem sempre alguém em pior situação". Tal comparação, que parece humanizar e aparentemente tornam mais generosas as pessoas pobres, diminuindo o impacto do "pouco ganho" ou das circunstâncias desvantajosas de vida, sinaliza para um diferencial com a classe média, que no cotidiano assistencial, sobretudo através das atividades coletivas, evita o contato com segmentos pobres, mais pauperizados, talvez pelo temor em se identificar negativamente, em virtude de a tendência de ascensão social ser o horizonte. Dessa maneira, não reforçam uma cultura cívico-democrática em relação ao serviço público.

As duas equipes de profissionais igualmente sinalizaram que a origem de classe dos usuários dos CAPS se situa entre as classes D e E e "baixa renda" ou "renda mais baixa", alguns profissionais rotulando-os de maneira ultragenérica como "susdependentes", por depender dos serviços do SUS. Neste sentido, o endereçamento do serviço como um direito sequer é invocado.

Usuários e familiares reforçam tal identidade ao afirmar que as "classes mais necessitadas", "mais pobres", "quem têm pouco recurso" é que seriam majoritárias no SUS.

Corroborando tal fato, Barata (2008), ao analisar o acesso e uso de serviços de saúde no Brasil, a partir da Pesquisa Nacional de Amostra por Domicílio PNAD (2003), configura como perfil dominante dos usuários do SUS: 61,9\% sexo feminino, 51,9\% etnia negra. Majoritariamente, os usuários do SUS estão situados em relação à renda entre meio a um salário mínimo (SM) (23,8\%), acompanhados dos que ganham até meio SM $(22,8 \%)$ e dos que se localizam na faixa de um a dois SM $(22,4 \%)$, o que totaliza um percentual de $46,6 \%$ dos usuários do SUS 
com renda per capita até um SM, ou seja, configuram os segmentos pobres da sociedade.

Logo, o CAPS, como parte do SUS, persiste distante da cidadania plena, como um serviço focalizado, parecendo figurar como um contraponto do horizonte da lógica do mercado. O horizonte do cidadão consumidor parece contornar as falas dos diferentes segmentos sociais, sobretudo de alguns profissionais que não conseguem visualizar que quem compra os serviços é igualmente dependente, seja da lógica do mercado, seja de determinadas ofertas, que limita e destitui o exercício da cidadania plena.

Todos admitem que alguns segmentos de classe média percebidos por determinadas insígnias econômicas (ter carro ou "aparência diferente") ou distintivo escolar ("faz faculdade", é "formado", tem curso superior) utilizam ambos os CAPS, configurando um usuário do tipo minoritário, "poucos classe média", mais evidenciados no cotidiano assistencial do serviço da região Nordeste.

Os profissionais identificam que os segmentos de baixa renda demandam uma atenção integral, trazendo junto com a demanda por assistência em saúde mental as determinadas pela questão social, preponderando aquelas relacionadas à acessibilidade ao serviço (transporte, passe livre/vale transporte), bem como outras inerentes às condições básicas de sobrevivência, tais como comida, acesso a Benefício de Prestação Continuada, e as ligadas à sua imagem social deteriorada, relacionadas ao preconceito.

Ambas as equipes reconhecem que, com a melhoria nas condições econômicas, a ascensão de determinados grupos para os segmentos médios da sociedade traz consigo a tendência de pessoas e famílias buscarem planos privados de saúde. Ou seja, a classe média busca privilégios, atenção particular, pouco usufruindo dos direitos sociais e se impregnando de uma cultura cívico-solidária. Reforça com sua conduta a saúde como uma mercadoria, metamorfoseando os direitos inerentes à cidadania plena em mero consumo adquirido pela via do mercado. Ativa-se assim o individualismo que

conspira contra a capacidade coletiva de articular valores comuns, construir referências simbólicas de identidades e lugares partilhados e imaginar instituições portadoras de futuro [...] a privatização dos serviços urbanos altera a produção dos espaços urbanos capturados pela lógica privada e privatizadora de capitais que circulam no mercado global, altera os modos de intervenção política, agora reduzidas à regulação dos mercados, não mais no registro das políticas públicas. (Telles e Henry, 2005, p. 30) 
Usuários do equipamento nordestino reconhecem o serviço como "misto", ou seja, utilizado por outros segmentos de classe que não apenas a classe "baixa", embora reconheçam ser essa a dominante. Tal fato ocorre em função da inexistência de serviços privados de saúde mental, no município da região Nordeste em estudo, com exceção de consultas médicas, no modelo liberal, associada à ausência de cura do transtorno mental, o que exige uma atenção contínua, que onera as famílias e para os quais os planos de saúde oferecem um rol de serviços limitados, restrito a determinado número de consultas médicas e sessões de psicoterapia. Tais condicionantes tendem a vulnerabilizar as famílias de segmentos médios da sociedade, tendentes a processos de empobrecimento e crescente busca por assistência pública em saúde, o que já ocorre com os procedimentos de alto custo.

Em relação à classe média, o grupo de profissionais, usuários e familiares dos dois equipamentos, mas mais detalhadamente do CAPS nordestino, que convivem de maneira mais intensa com esse estrato no cotidiano assistencial, identificam singularidades nesse segmento, no sentido de ter o preconceito mais visibilizado, na perspectiva de "esconder" da sociedade a pessoa da família que tem um diagnóstico de transtorno mental; ter um comportamento de esquiva, "não querer se misturar", por meio das ações grupais/coletivas, com segmentos de baixa renda no cotidiano do serviço, fato também informado pelos profissionais; ter menor reconhecimento simbólico pelos serviços de seus profissionais, visto o pobre ter um sentimento de gratidão expresso e demandar carinho e uma relação mais afetuosa, menos impessoal.

As duas equipes reconhecem que a classe média, ao usufruir dos CAPS, o faz de maneira seletiva, pontual, buscando mais a assistência médica, psicológica e psicofarmacológica.

Os profissionais do CAPS da região Sudeste admitem que para abordar pessoas de classe "baixa" é exigido uma adequação de linguagem, pelos parcos recursos simbólicos, cognitivos e comunicacionais que disponibilizam, remetendo tal questão à sua dimensão preponderantemente técnica. As questões políticas subjacentes às relações sociais são parcamente exploradas pelos diferentes grupos pesquisados, ficando restrita a alguns profissionais que identificam as relações de poder que atravessam o cotidiano assistencial.

A equipe de trabalhadores do CAPS situado na região nordestina reconhece que o preconceito perpassa as relações dos profissionais com os segmentos de 
classe média e segmentos de baixa renda que demandam mais explicitamente direitos, tendo argumentos mais elaborados para reivindicações nesse horizonte, deixando os profissionais em situação mais desconfortável, pois estão acostumados a lidar com um público que reivindica menos e tem uma relação mais permeada pela gratidão e menos pelos signos dos direitos/cidadania. $\mathrm{O}$ espírito missionário em relação aos pobres parece se aguçar nesse cenário, que persiste pouco permeável à lógica da cidadania. É admitida ainda a dificuldade em apreender que o CAPS é um serviço pluriclassista, pois com o crescente uso por segmentos de classe média, predomina entre os profissionais um entendimento de que tal categoria deveria ter uma atenção pela via do mercado privado, numa concepção de que "podem pagar" pelos serviços, sem sobrecarregar o SUS.

Em todos os grupos focais com profissionais é reconhecida a importância de fortalecimento do SUS, que tendeu historicamente, no imaginário social, a ser percebido como um serviço para pobres e de "péssima qualidade", como a maioria dos serviços públicos é representado socialmente. Sua assunção universal como um direito social é requerido por alguns profissionais, na defesa da cidadania plena, como um bem público e de qualidade e para maiores investimentos governamentais. Muito embora o reconhecimento do SUS como um direito social tenha atravessado algumas falas de profissionais, usuários e familiares, as discussões em torno da cidadania e da cultura cívica ainda carecem de maiores investimentos, haja vista percepção de que ter esse serviço é um privilégio, por "não precisar pagar nada", sobretudo entre os dois últimos segmentos. Raros foram os depoimentos que admitiram ser o CAPS fruto dos impostos, consequentemente, um direito coletivo. A lógica do direito e da cidadania, mais uma vez, pouco fundamentou as falas dos diferentes sujeitos da pesquisa. Mas há uma perspectiva de uma das gestoras do serviço da região Sudeste que se a classe média, com todo seu capital sociocultural, se implicasse com o SUS, poderia fazer uma revolução, visto que "se a classe média entrasse aqui [...] fizesse os questionamentos que ela faz enquanto ela paga o plano de saúde... aaaah! a gente ia ter uma revolução no sistema de saúde. Ou os governos iam ter que bancar um SUS para todo mundo, ou ia acabar".

Ou seja, a universalização do SUS é saudada desde que a classe média não se comporte como mera consumidora de serviços, mas como sujeito dos processos de construção da cidadania ativa, sendo atuante, reivindicadora e propositiva, utilizando em prol do SUS todos seus recursos simbólicos, por agregar informação e poder de pressão, considerados estratégicos para promover mudanças substantivas. 


\section{Considerações finais}

Nos dois CAPS que serviram de base empírica da pesquisa, observam-se várias convergências na concepção de classe social entre os sujeitos da pesquisa, concebida muito mais por suas relações econômicas que políticas. Há tendência de ultrageneralização das diferentes classes e frações de classe homogeneizadas em suas condições culturais e estilos de vida. O CAPS é visualizado como um serviço interclassista, por abrigar diferentes classes sociais e frações de um mesmo segmento, o que se retrata nas relações entre os profissionais e destes com os usuários. Os registros da lógica da cidadania ainda são escassos no cotidiano assistencial, persistindo a subalternização dos usuários de baixa renda e dificuldades no manejo de usuários oriundos dos estratos de média e de baixa renda, com poder de pressão política por direitos. Historicamente, os serviços de saúde mental conformaram-se como um serviço focado nos segmentos de baixa renda, para os pobres, tendo que se pluralizar e se conformar como um serviço pluriclassista, pela própria perspectiva imposta por sua universalização, e reconhecimento da cidadania plena dos brasileiros, a partir da Constituição de 1988. Mas observa-se a escassa cultura cívico-solidária para fortalecer os serviços públicos de saúde, ganhando proeminência a lógica do mercado como o principal contorno nas relações assistenciais cotidianas, havendo necessidade de maior politização do dia a dia, o que pode ser facilitado pela maior criticidade envolvendo as relações sociais.

Recebido em 3/9/2012 - Aprovado em 11/3/2013

\section{Referências bibliográficas}

AMARANTE, P. D. O homem e a serpente: outras histórias para a loucura e a psiquiatria. Rio de Janeiro: Fiocruz, 1996.

BARATA, Rita Barradas. Acesso e uso de serviços de saúde: considerações sobre os resultados da pesquisa de condições de vida 2006. São Paulo em Perspectiva, São Paulo, v. 22, n. 2, p. 19-29, jul./dez. 2008.

BARDIN, L. Análise de conteúdo. Lisboa: Edições 70, 1979. 
BASAGLIA, F. A instituição negada. 2. ed. Rio de Janeiro: Graal, 1985.

CAMPOS, R. O.; BACCARI, I. P. A intersubjetividade no cuidado à saúde mental: narrativas de técnicos e auxiliares de enfermagem de um Centro de Atenção Psicossocial. Ciência \& Saúde Coletiva, Rio de Janeiro, v. 16, n. 4, p. 2051-2058, 2011.

CASTEL, R. A ordem psiquiátrica: a idade de ouro do alienismo. 2. ed. Rio de Janeiro: Graal, 1978.

CENSO DEMOGRÁFICO/IBGE. Censo Demográfico 2010: características da população e dos domicílios: resultados do universo. Rio de Janeiro: IBGE, 2010.

DAGNINO, E.; OLVERA, A. J.; PANFICHI, A. Por uma outra leitura da disputa pela construção democrática na América Latina. In: et al. A disputa pela construção democrática na América Latina. Rio de Janeiro: Paz e Terra, 2008.

DUARTE, L. F. D. Da vida nervosa nas classes trabalhadoras urbanas. 2. ed. Rio de Janeiro: Jorge Zahar, 1988.

DUNNINGHAN, W. Classes sociais e transtornos mentais. Salvador: Fator Editora Psicanálise, 1988.

FONSECA, Liana Maria Gesteira. Sofrimento difuso nas classes populares no Brasil: uma revisão da perspectiva do nervoso. In: VASCONCELOS, E. M (Org). Abordagens psicossociais. São Paulo: Hucitec, 2008. v. 2, p. 171-228.

GOFFMAN, I. Manicômios, prisões e conventos. 4. ed. São Paulo: Perspectiva, 1992.

HELLER, A. O cotidiano e a história. Rio de Janeiro: Paz e Terra, 1989.

LUDERMIR, Ana Bernarda. Desigualdades de classe e gênero e saúde mental nas cidades. Physis, Rio de Janeiro, v. 18, n. 3, p. 451-467, 2008.

MILLES, A. O doente mental na sociedade contemporânea. Rio de Janeiro: Zahar Editores, 1982.

MIRANDA, L. et al. Dos grupos focais aos grupos focais narrativos: uma descoberta no caminho da pesquisa. In: CAMPOS, R. O. et al. Pesquisa avaliativa em saúde mental: desenho participativo e efeitos da narratividade. São Paulo: Hucitec, 2008.

MOFFATT, A. Psicoterapia do oprimido: ideologia e técnica da psiquiatria popular. 7. ed. São Paulo: Cortez, 1991.

NUNES, Everardo Duarte. Hollingshead e Redlich: a pesquisa sobre classe social e doença mental cinquenta anos depois. História, Ciências, Saúde, Manguinhos, Rio de Janeiro, v. 17, p. 125-40, jan./mar. 2010. 
RESENDE, Heitor. Política de saúde mental no Brasil: uma visão histórica. In: TUNDIS, S.; COSTA, N. Cidadania e loucura: políticas de saúde mental no Brasil. Petrópolis: Vozes, 1990.

ROTELLI, F. Desinstitucionalização. São Paulo: Hucitec, 1990.

SAFFIOTI, H. I. B. Gênero, patriarcado, violência. São Paulo: Editora Fundação Perseu Abramo, 2004.

SAMPAIO, J. J. C. Epidemiologia da imprecisão: processo saúde/doença mental como objeto da epidemiologia. Rio de Janeiro: Fiocruz, 1998.

SANTOS, T. Conceito de classes sociais. 3. ed. Petrópolis: Vozes, 1985.

SARACENO, B. Manual de saúde mental. São Paulo: Hucitec, 1999.

TELLES, Vera da Silva; HENRY, Etienne. Serviços urbanos, cidade e cidadania. In:

et al. (Orgs.). Serviços urbanos, cidade, cidadania. 2. ed. Rio de Janeiro: Lumen Juris, 2005.

VASCONCELOS, E. M. (Org.). Abordagens psicossociais: reforma psiquiátrica e saúde mental na ótica da cultura e das lutas populares. São Paulo: Hucitec, 2008. v. III. 